\title{
Comparison of whole body retention of I-131 in case humans thyroid cancer between model prediction and measurement
}

\author{
${\text { Brudecki Kamil }{ }^{1 *} \text {, Mroz Tomasz }}^{2}$,Janowski Paweł ${ }^{3}$ and Lorenc-Brudecka Jadwiga ${ }^{4}$ \\ ${ }^{1}$ Institute of Nuclear Physics, Polish Academy of Sciences, Radzikowskiego, Poland \\ ${ }^{2}$ Department of Cell Biology and Genetics, The Pedagogical University of Cracow, Poland \\ ${ }^{3}$ AGH University of Science and Technology, Mickiewicza, Poland \\ ${ }^{4}$ Zoological Museum of Jagiellonian University, Ingardena, Poland
}

\begin{abstract}
This paper undertakes the attempt to evaluate the conformity of the iodine biokinetic model with the experimental data. Experimental data come from several publications. Most of them describe the ${ }^{131} \mathrm{I}$ retention among patients subjected to the therapy of the thyroid cancer. In these experimental studies 286 patients participated and administrated activity range was from $350 \mathrm{kBq}$ to $7400 \mathrm{MBq}$. Computer simulations have been conducted based on four models. Two of them were designed for nuclear medicine (model developed by Committee on Medical Internal Radiation Dose and model developed by Johansson in 2003) and two of them for the radiological protection (current ICRP model and the model proposed by Legget in 2010). Simulations were conducted using the SAAM II software. The best correlation with experimental results was obtained using the Johansonns model, while the worst using MIRD model. Leggets and ICRP models were ranked in the middle. For iodine uptake at $10 \%$, the model proposed by Johansson provides the reality of almost entire duration of the experiment (120 hours) very well.
\end{abstract}

\section{Introduction}

Iodine has about 36 unstable isotopes. One of them is the radioactive ${ }^{131} \mathrm{I}$, which origin is often purely anthropogenic. It has a half-life of 8.0252(6) days, emitting $\beta$ radiation and the immediately following $\gamma$ radiation. Because of ${ }^{131} \mathrm{I}$ decay there is stable ${ }^{131} \mathrm{Xe}$ created. ${ }^{131} \mathrm{I}$ is obtained in the process of the nuclear fission of the uranium or plutonium in nuclear reactors, or by thermal neutron activation of ${ }^{130} \mathrm{Te}$ in ${ }^{130} \mathrm{Te}(n, \gamma){ }^{131} \mathrm{Te} \rightarrow{ }^{\beta^{-}} \rightarrow{ }^{131} \mathrm{I}$ reaction.

The first treatment using ${ }^{131} \mathrm{I}$ was conducted in 1942 for the hyperthyroidism affliction [1]. It is currently estimated that $90 \%$ of all treatments in nuclear medicine take place using this isotope $[2,3]$. It was used primarily for the diagnosis and treatment of the thyroid gland diseases, where natural affinity of this organ to iodine is used. Radiotherapy is most often used for the treatment of hyperthyroidism and thyroid cancer. ${ }^{131} \mathrm{I}$ is also used in tests of kidney and the bladder functions. Taking into consideration the wide use of ${ }^{131} \mathrm{I}$ it is very important for the theoretical models to predict the iodine behaviour in the human body to describe reality as precisely as possible. This is of importance for the widely-understood safety in the nuclear medicine. The goal of this paper is to evaluate the conformity of several models of iodine biokinetic with the experimental data obtained from the patients treated with ${ }^{131} \mathrm{I}$.

\section{Material and methods}

The process of obtaining our results consisted of three steps. The first one was to find the experimental data. Next one, using biokinetic models and SAMM II software we simulated ${ }^{131}$ I retention in human body directly, in the same conditions as in the case of obtaining experimental data. Finally, we compared the results from previous steps and drew conclusions.

\section{Experimental data}

The experimental data were taken from five selected publications. In most cases, they describe the retention of ${ }^{131} \mathrm{I}$ in patients' bodies subjected to the therapy of the thyroid cancer. In two of them retention has been marked based on the measurements of ${ }^{131} \mathrm{I}$ in patients' urine $[4,5]$. Patients were divided into three groups depending on the activity given $(3700 \mathrm{MBq}, 5550 \mathrm{MBq}$ and $7400 \mathrm{MBq}$ ). In the first study 83 patients participated ( 22 males and 61 females with age ranging from 22 to 79). Urine samples were collected 6, 12, 18, 24, 48, 72, 96 and 120 hours after the oral administration of iodine. Then activity have been measured in a well counter Capintec CRC25. In the second study 59 patients participated. Urine samples were collected 24, 48, 72, 96 and 120 hours after the oral administration of iodine. Activities have been measured in a beta - gamma probe model 491-40.

Another two publications describe whole body retention of ${ }^{131}$ I on the basis of external dose rate and effective half-life. In the first study 27 patients participated and in the second -69 [6,7]. The effective

Correspondence to: Brudecki Kamil, Institute of Nuclear Physics, Polish Academy of Sciences, Radzikowskiego, Poland; Tel: (+48 12) 662-8390; E-mail: kamil.brudecki@ifj.edu.pl

Key words: ${ }^{131}$ I, radioiodine therapy, biokinetic modelling, nuclear medicine

Received: November 02, 2016; Accepted: November 25, 2016; Published: November 29, 2016 
half-life was determined as $24.7 \mathrm{~h}$ and $18 \mathrm{~h}$ in the first and the second publication, respectively.

In the last publication $[8]{ }^{131}$ I effective half-life was estimated based on thyroid in vivo measurements. In this study 48 patients participated and the measurements were performed in a whole-body counter equipped with $6 \mathrm{NaI}(\mathrm{Tl})$ detectors. The estimated iodine-131 half-life was 21 hours. Detailed results from the publications mentioned above are presented in Table 1.

\section{Biokinetic modelling}

${ }^{131}$ I whole body retention at time $t$ was simulated on the basis of four biokinetic models. Two of them were designed for nuclear medicine and two of them for the radiological protection.

First biokinetic model used in our study was the model developed by Committee on Medical Internal Radiation Dose (MIRD)[9]. It is simple, monoexponential model. It includes specific uptakes in intestilne, liver, stomach and thyroid but does not include recycling of iodine due to the metabolism of secreted thyroid hormones. Thyroid uptake (u) was assumed on three levels: 5\%, 15\% and 25\%. Parameters of this model are presented in Table 2.

Second model used in presented study was the model developed by Johansson in 2003 [10]. This model also was designed for nuclear medicine purposes but it is more detailed than previous one. It includes recirculation of organically bound iodine and uptakes in GI track, kidneys, urinary bladder, salivary glands and thyroid. This model is also age-dependent and assumes any thyroid uptake $(\mathrm{u})$. The structure and parameters of the Johanssons model are presented in Figure 1.
In the case of models dedicated for radiological protection we decided to use current ICRP model and the model proposed by Legget in 2010 [11]. Figure 2 shows three compartment model presented by Riggs in 1952 and still being used by ICRP as its primary biokinetic model [12]. The structure of the model proposed by Legged is presented in Figure 3. and a baseline coefficients for adults are listed in Table 3. Both models describe the three most important subsystems of the iodine cycle in a human body: circulation of inorganic iodine, circulation of extrathyroid organic iodine and thyroidal iodine (synthesis, storage and secretion of thyroid hormones). The model proposed by Legget was evaluated against experimental data. The models predictions were compared with experimental data after intravenously injection in blood, urine, salivary glands plus gastric secretion and thyroid. Experimental data were very precise, but unfortunately, they describe iodine retention in a very short period- 3 hours [13-16].

\section{Results and discussion}

Results of the comparison of the experimental data with computer simulations for each model are presented in Figure 4- 6. The best consistency with the experimental results was obtained using the Johansonns model, while the worst using MIRD model. Leggets and ICRP models were ranked in the middle. The time, in which each models prediction lie in-between empirical range (average \pm 2 sigma), related to total simulation time $(120 \mathrm{~h})$ is approximately equal: $27 \%$, $45 \%, 65 \%, 24 \%, 33 \%, 43 \%, 23 \%$ and $29 \%$ respectively for Johansonns model $u=30 \%, u=20 \%, u=10 \%$, MIRD model $u=25 \%, u=15 \%, u=5 \%$, Riggs model and Leggett model. For the models tested also correlation analysis was performed, relating experimental data and the results of simulations (Figure 7). The highest Pearson product-moment

Table 1. Comparison of the percentage ${ }^{131} \mathrm{I}$ whole body retention in experimental studies [4-8].

\begin{tabular}{|c|c|c|c|c|c|c|c|c|c|c|}
\hline $\begin{array}{c}t \\
{[\mathbf{h}]}\end{array}$ & $\begin{array}{c}\text { Demir }[4] \\
N=48 \\
3700 \mathrm{MBq}\end{array}$ & $\begin{array}{c}\text { Willegaignon [5] } \\
N=12 \\
3700 \mathrm{MBq}\end{array}$ & $\begin{array}{c}\text { Demir [4] } \\
N=18 \\
5550 \mathrm{MBq}\end{array}$ & $\begin{array}{c}\text { Willegaignon [5] } \\
N=22 \\
5550 \mathrm{MBq}\end{array}$ & $\begin{array}{c}\text { Demir [4] } \\
N=17 \\
7400 \mathrm{MBq}\end{array}$ & $\begin{array}{c}\text { Willegaignon [5] } \\
N=25 \\
7400 \mathrm{MBq}\end{array}$ & $\begin{array}{c}\text { Marriot* }[6] \\
N=27 \\
T_{\text {eff }}=24.7 \mathrm{~h}\end{array}$ & $\begin{array}{c}\text { Kramer }^{*}[7] \\
N=48 \\
T_{\text {eff }}=21 \mathrm{~h}\end{array}$ & $\begin{array}{c}\text { North* }[8] \\
N=69 \\
T_{\text {eff }}=18 \mathrm{~h}\end{array}$ & Average \\
\hline 6 & $79 \pm 11$ & - & $78 \pm 10$ & - & $78 \pm 10$ & - & 85 & 82 & 79 & $81 \pm 2$ \\
\hline 12 & $62 \pm 9$ & - & $63 \pm 8$ & - & $61 \pm 8$ & - & 71 & 67 & 63 & $66 \pm 4$ \\
\hline 18 & $52 \pm 9$ & - & $54 \pm 5$ & - & $52 \pm 7$ & - & 60 & 55 & 50 & $55 \pm 4$ \\
\hline 24 & $44 \pm 6$ & $31 \pm 10$ & $44 \pm 6$ & $29 \pm 8$ & $43 \pm 5$ & $33 \pm 10$ & 51 & 45 & 40 & $42 \pm 7$ \\
\hline 48 & $13 \pm 2$ & $11 \pm 7$ & $12 \pm 2$ & $9 \pm 5$ & $13 \pm 3$ & $12 \pm 7$ & 26 & 21 & 16 & $17 \pm 6$ \\
\hline 72 & $6 \pm 0.4$ & $4 \pm 4$ & $6 \pm 0.7$ & $3 \pm 2$ & $6 \pm 0.6$ & $5 \pm 4$ & 13 & 9 & - & $8 \pm 4$ \\
\hline 96 & $3 \pm 0.1$ & $2 \pm 2$ & $3 \pm 0.7$ & $1 \pm 1$ & $4 \pm 0.4$ & $2 \pm 2$ & - & 4 & - & $3 \pm 1$ \\
\hline 120 & $1.1 \pm 0.1$ & $0.7 \pm 1$ & $1.4 \pm 0.1$ & $0.4 \pm 0.4$ & $1.2 \pm 0.2$ & $0.8 \pm 1.1$ & - & 2 & - & $1 \pm 1$ \\
\hline
\end{tabular}

* Results obtained on the base of proposed iodine effective half-life $T_{\text {eff }}$

Table 2. Biological parameters of the fractional distribution functions $\mathrm{a}(\mathrm{t})=\mathrm{a}_{1} \mathrm{e}^{-\lambda 1 \mathrm{t}}+\mathrm{a}_{2} \mathrm{e}^{-\lambda 2 \mathrm{t}}+\mathrm{a}_{3} \mathrm{e}^{-\lambda 3 \mathrm{t}}+\mathrm{a}_{4} \mathrm{e}^{-\lambda 4 t}$ for the Medical Internal Radiation Dose Committee model [9].

\begin{tabular}{|c|c|c|c|c|c|c|c|c|c|}
\hline thyroid uptake & source organ & $a_{1}$ & $\lambda_{1}\left[h^{-1}\right]$ & $a_{2}$ & $\lambda_{2}\left[\mathbf{h}^{-1}\right]$ & $\mathbf{a}_{3}$ & $\lambda_{3}\left[h^{-1}\right]$ & $a_{4}$ & $\lambda_{4}\left[\mathrm{~h}^{-1}\right]$ \\
\hline \multirow[t]{5}{*}{$5 \%$} & intestine & 0.169 & 0.0879 & 0.000502 & 0.0488 & -0.0000262 & 0.00492 & 0.0000579 & 0.000554 \\
\hline & liver & 0.0156 & 0.0879 & -0.000390 & 0.0488 & -0.00109 & 0.00492 & 0.00139 & 0.000554 \\
\hline & stomach & 0.149 & 0.0879 & 0.000459 & 0.0488 & -0.0000245 & 0.00492 & 0.0000529 & 0.000554 \\
\hline & thyroid & -0.0517 & 0.0879 & - & - & - & - & 0.0519 & 0.000554 \\
\hline & total body & 0.944 & 0.0879 & - & - & - & - & 0.056 & 0.000554 \\
\hline \multirow{5}{*}{$15 \%$} & intestine & 0.169 & 0.0994 & 0.000982 & 0.0488 & -0.0000669 & 0.00492 & 0.000152 & 0.000498 \\
\hline & liver & 0.0159 & 0.0994 & -0.00130 & 0.0488 & -0.00313 & 0.00492 & 0.00408 & 0.000498 \\
\hline & stomach & 0.149 & 0.0994 & 0.000882 & 0.0488 & -0.0000629 & 0.00492 & 0.000140 & 0.000498 \\
\hline & thyroid & -0.154 & 0.0994 & - & - & - & - & 0.154 & 0.000498 \\
\hline & total body & 0.836 & 0.0994 & - & - & - & - & 0.164 & 0.000498 \\
\hline \multirow{5}{*}{$25 \%$} & intestine & 0.169 & 0.114 & 0.00115 & 0.0488 & -0.0000962 & 0.00492 & 0.000221 & 0.000444 \\
\hline & liver & 0.0159 & 0.114 & -0.00206 & 0.0488 & -0.00506 & 0.00492 & 0.00667 & 0.000444 \\
\hline & stomach & 0.149 & 0.114 & 0.00103 & 0.0488 & -0.0000913 & 0.00492 & 0.000204 & 0.000444 \\
\hline & thyroid & -0.255 & 0.114 & - & - & - & - & 0.255 & 0.000444 \\
\hline & total body & 0.279 & 0.114 & - & - & - & - & 0.271 & 0.000444 \\
\hline
\end{tabular}




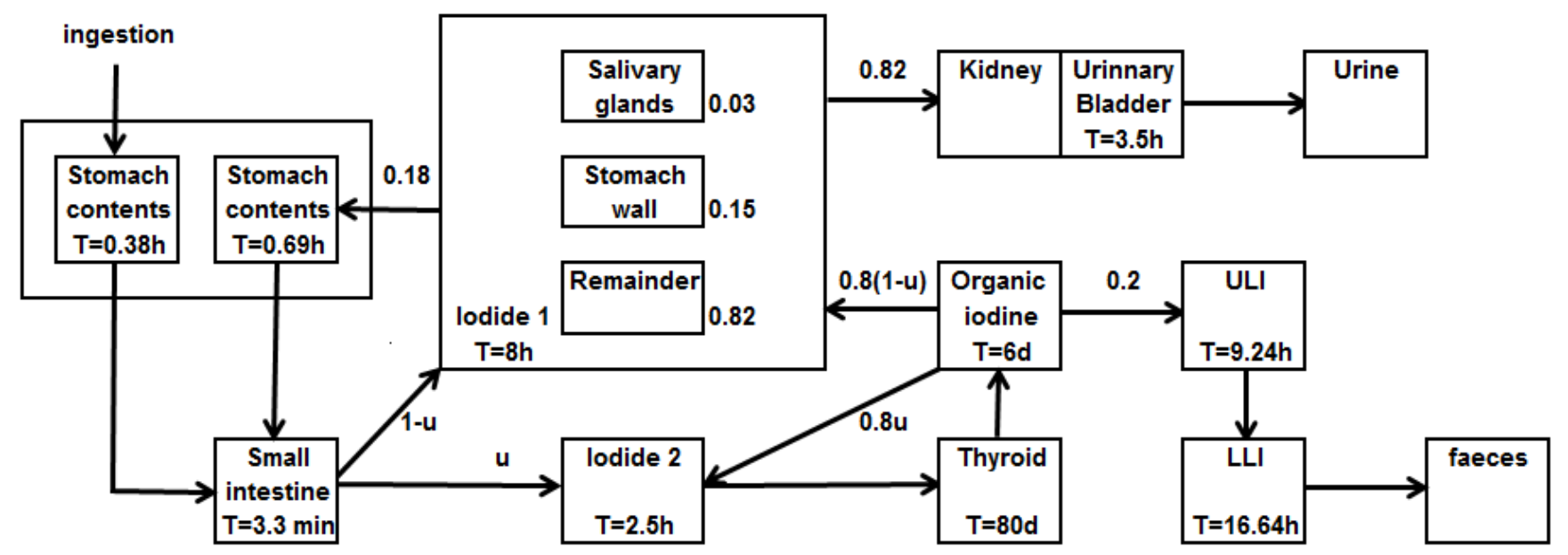

Figure 1. Biokinetic model after oral intake of iodide proposed by Johansson. $\mathrm{U}$ is uptake in the thyroid. Parameters are given for adults in terms of fractional distributions [10].

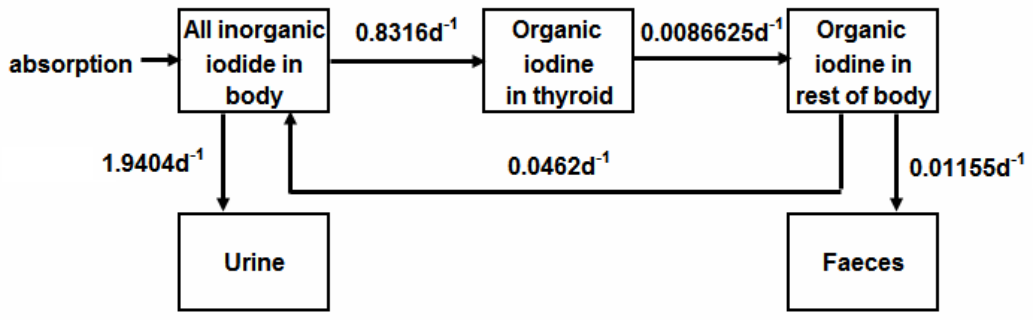

Figure 2. Iodine biokinetic model used by ICRP [12].

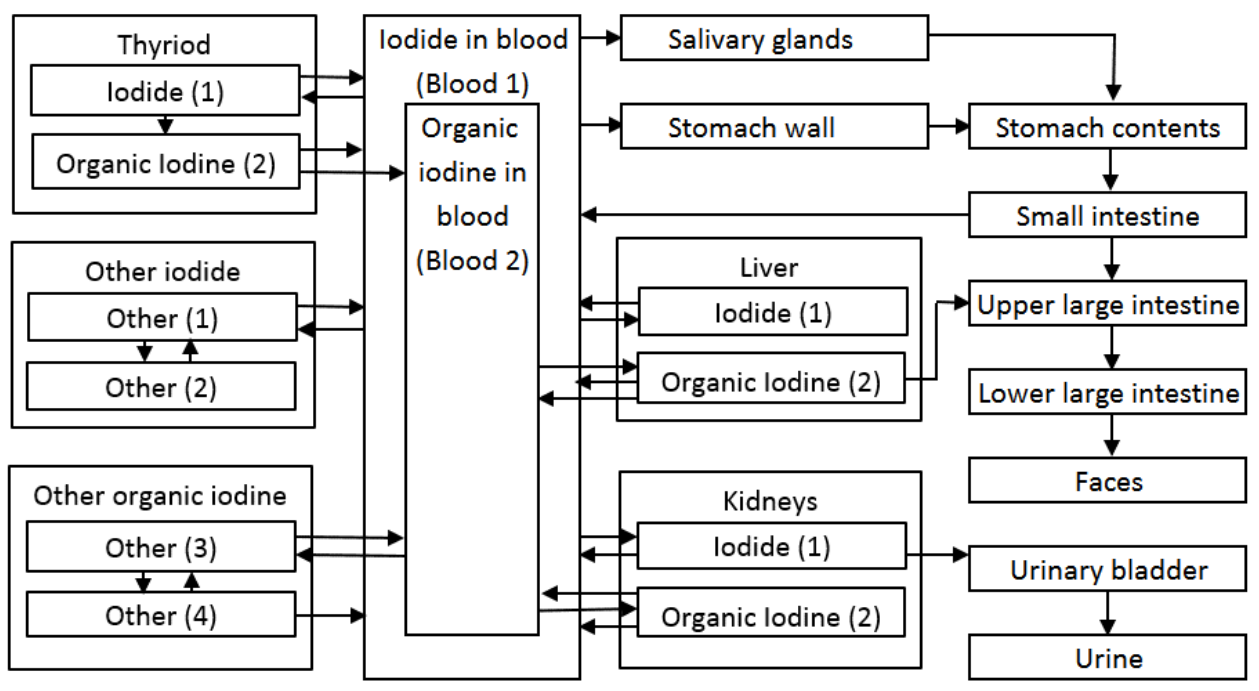

Figure 3. Structure of the Leggett ${ }^{131} \mathrm{I}$ biokinetic model [11].

correlation coefficients, 0.977 and 0.934 describe Johansons model, for $10 \%$ and $20 \%$ of iodine uptake, respectively. The lowest values, 0.393 and 0.523 describe correlation between experimental data and models: Riggs and MIRD with iodine uptake at the level of $25 \%$, respectively.

For iodine uptake at $10 \%$ the model proposed by Johansson provides the reality of almost the entire duration of the experiment (120 hours) very well. The greatest variation of the measured quantities reaches less than $6 \%$. The situation looks a little worse for iodine uptake at $20 \%$, there are very good predictions we get through the first 48 to 72 hours. The maximum deviation of measurements amounted to approx. $13 \%$ after 120 hours after administration of the radioiodine.

The model proposed by MIRD and models for radiological protection, are much worse in the correct prediction of measured results. In general, these three models have the tendency to underestimating of the retention of iodine in the first 24 hours and overestimating it after 48 hours. In the first 24 hours, the biggest differences were 25\%, 18\% 


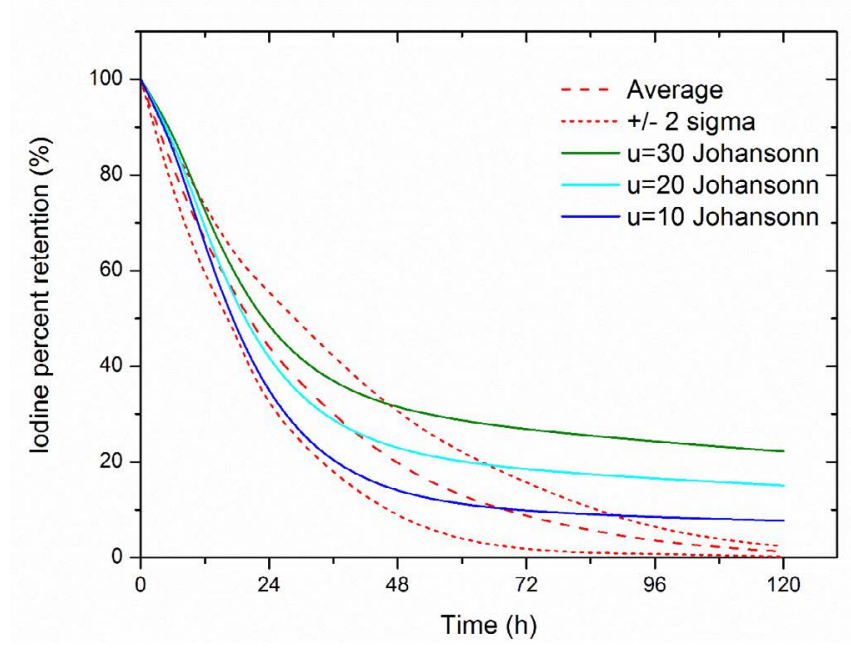

Figure 4. Comparison of the experimental data with computer simulations in case Johansonn model (Average-average percentage ${ }^{131}$ I wholebody retention in experimental studies, table 1, $\mathrm{u}$ - percentage thyroid uptake).

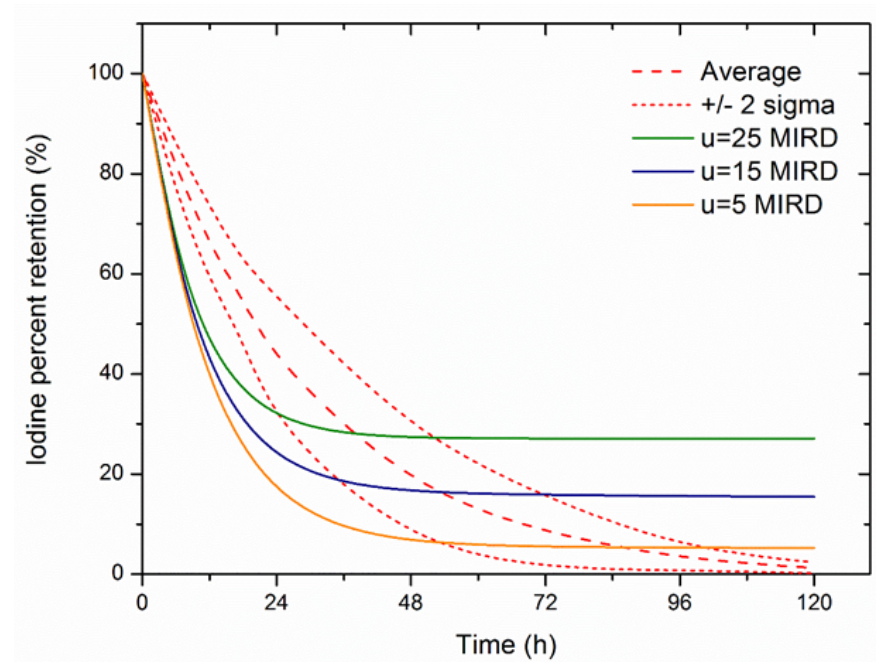

Figure 5. Comparison of the experimental data with computer simulations in case MIRD model(Average-average percentage ${ }^{131}$ I whole body retention in experimental studies, table 1, u- percentage thyroid uptake).

and $15 \%$ for the models proposed by MIRD $(\mathrm{u}=15 \%)$, Rigs and Legget. After $48 \mathrm{~h}$, the largest differences were $29 \%, 19 \%$ and $15 \%$, each for the models proposed by the Rigs, Legget and MIRD $(u=15 \%)$. It is very important that models designed for radiological protection are applied for a fully healthy people, but are not used, as in the presented studies, for patients with thyroid cancer. This may explain discrepancies between modelling and experimentally measured values. Even though these models were developed for radiation protection, they may be used in nuclear medicine under certain conditions, especially the model proposed by Legget which describes the retention of iodine in all the key organs and therefore it is more specific than the Johansson's model.

From the presented results, it is also apparent in the case of tumour diseases of the thyroid iodine uptake and on average has a range from $10 \%$ to $20 \%$, while the level of uptake of iodine is recommended by the ICRP is $30 \%$.

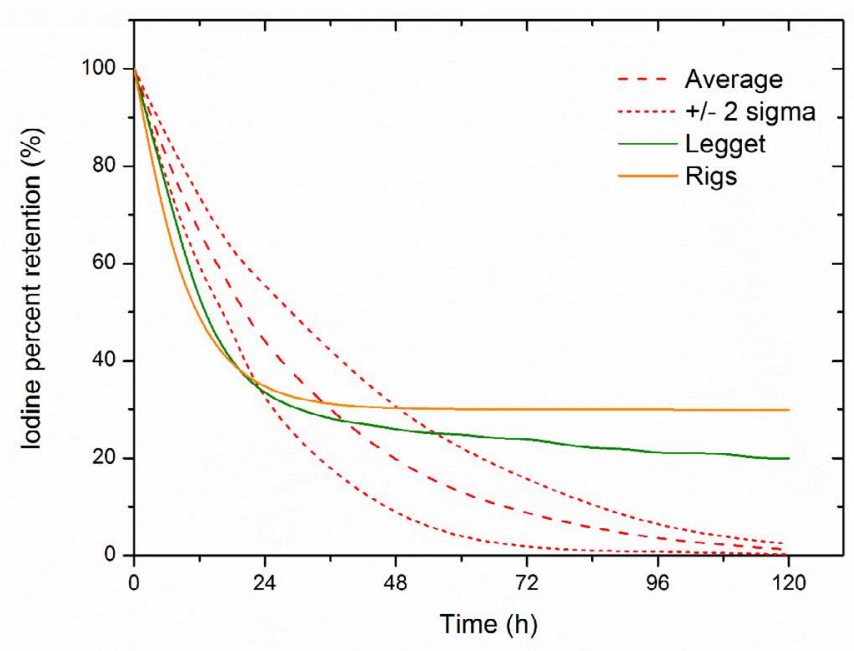

Figure 6. Comparison of the experimental data with computer simulations in case Leggett and Rigs models (Average- average percentage ${ }^{131}$ I whole body retention in experimental studies, table 1).
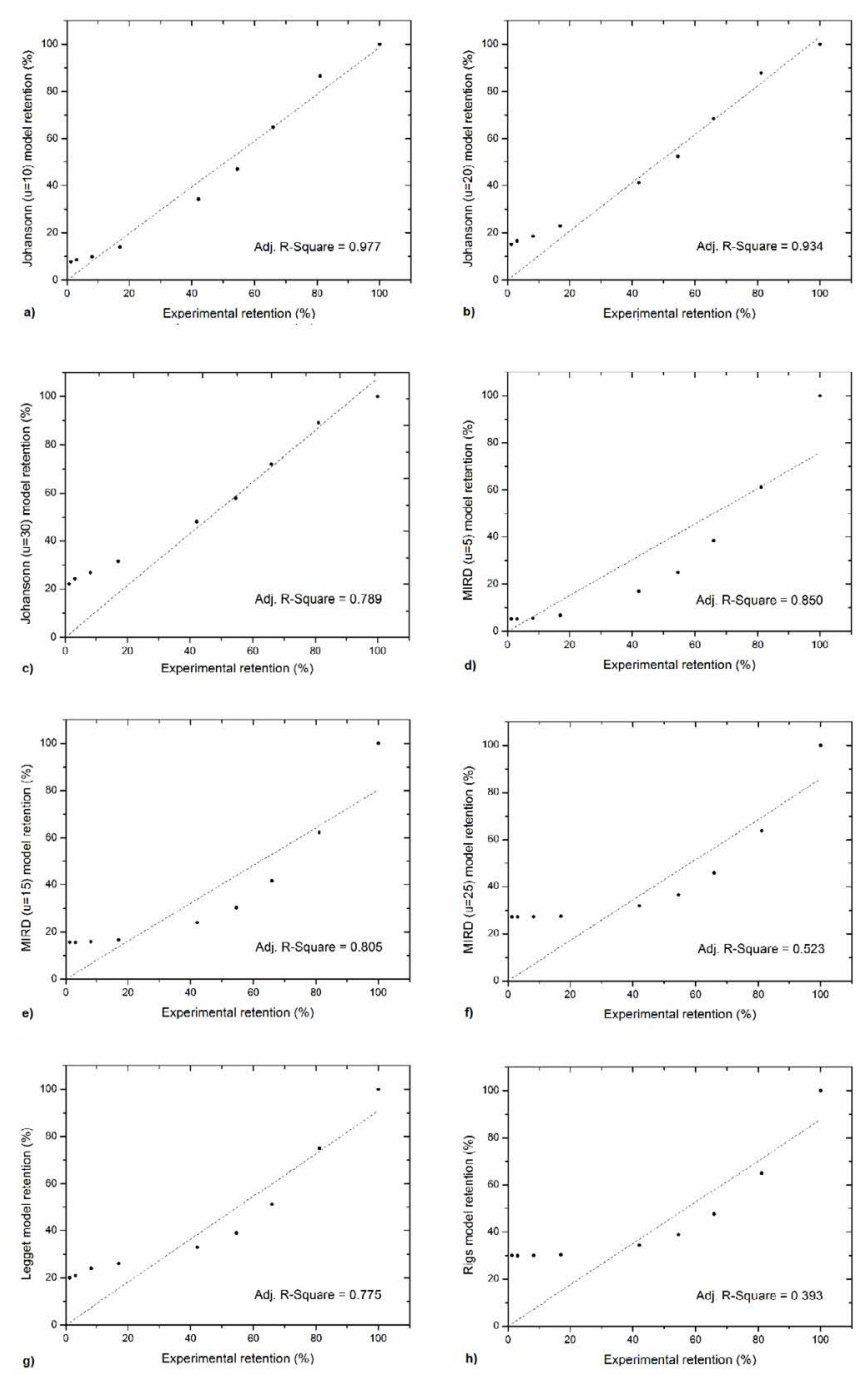

Figure 7. Correlations between model predictions and measurement in case: a) Johansonn $\mathrm{u}=10 \%$, b) Johansonn $\mathrm{u}=20 \%$, c) Johansonn $\mathrm{u}=30 \%$, d) MIRD $\mathrm{u}=5 \%$, e) MIRD $u=15 \%$, f) MIRD $\mathrm{u}=25 \%$, g) Leggett, h) Rigs 


\section{Acknowledgments}

This work was supported by the National Science Centre, Poland [2014/15/B/NZ7/00925].

\section{References}

1. Saenger EL, Kereiakes JG, Soddi VJ, David R (1979) Radiotherapeutic agents: properties, dosimetry, and radiobiologic considerations. Seminars Nucl Med 9: 72-84. [Crossref]

2. International Commission on Radiological Protection (2004) Release of patients after therapy with unsealed radionuclides. Ann ICRP 34: 1-79. [Crossref]

3. United Nations Scientific Committee on the Effects of Atomic Radiation (2001). Sources and effects of ionizing radiation. Report to the general assembly with annexes. Vienna: United Nations.

4. Demir M, Parlak Y, Cavdar I, Yeyin N, Tanyildizi H, et al. (2013) The evaluation of urine activity and external dose rate from patients receiving radioiodine therapy for thyroid cancer. Radiat Prot Dosimetry. 156: 25-29. [Crossref]

5. Willegaignon J, Stabin MG, Guimaraes MI, Malvestiti LF, Sapienza MT, et al. (2006) Evaluation of the potential absorbed doses from patients based on whole-body 1311 clearance in thyroid cancer therapy. Health Phys. 91: 123-127. [Crossref]

6. Marriott CJ, Webber CE, Gulenchyn KY (2007) Radiation exposure for 'caregivers' during high-dose out-patients' radioiodine therapy. Radiat Prot Dosim 123: 62-67. [Crossref]

7. North DL, Shearer DR, Hessessey JV, Donovan GL (2002) Effective half-life of I-131 in thyroid cancer patients. Health Phys 81: 325-329. [Crossref]
8. Kramer GH, Hauck BM, Chamberlain MJ (2002) Biological half-life of iodine in adults with intact thyroid function and in athyreotic persons. Radiat Prot Dosimetry 102:129135. [Crossref]

9. MIRDDoseEstimateReportNo.5. Summaryofcurrentradiationdoseestimatestohumans from 123I, 124I, 125I, 126I, 130I, 131I and 132I as sodium iodide (1975) J Nucl Med. 16: $857-860$.

10. Johansson L, Leide-Svegborn S, Mattsson S, Nosslin B (2003) Biokinetics of Iodide in Man: Refinement of Current ICRP Dosimetry Models. Cancer Biotherapy and Radiopharmaceuticals 18: 445-450.

11. Leggett RW (2010) A physiological systems model for iodine for use in radiation protection. Rad Res 174: 496-516. [Crossref]

12. Riggs DS (1952) Quantitative aspects of iodine metabolism in man. Pharmacol Rev 4: 284-370. [Crossref]

13. Alexander WD, Shimmins J, Robertson JWK, Horton PW, McLarty DG, et al. (1970) Radioisotope studies of thyroid function and thyroid hormone metabolism. In Dynamic studies with radioisotopes in medicine. Proceedings of a symposium. Rotterdam 179. 190

14. Berson SA, Yalow RS, Sorrentino J, Roswit B (1952) The determination of thyroidal and renal plasma ${ }^{131} \mathrm{I}$ clearance rates as a routine diagnostic test of thyroid dysfunction. J Clin Invest 31: 141-158. [Crossref]

15. Hays MT, Solomon DH (1965) Influence of the gastro intestinal iodide cycle on the early distribution of radioactive iodide in man. J Clin Invest 44: 117-127. [Crossref]

16. Wagner HN, Nelp WB, Dowling JH (1961) Use of neutron activation analysis for studying stable iodine uptake by the thyroid. J Clin Invest 40: 1984-1992. [Crossref]

Copyright: $@ 2016$ Kamil B. This is an open-access article distributed under the terms of the Creative Commons Attribution License, which permits unrestricted use, distribution, and reproduction in any medium, provided the original author and source are credited. 